\title{
Observations of turbulence within the surf and swash zone of a field-scale sandy laboratory beach
}

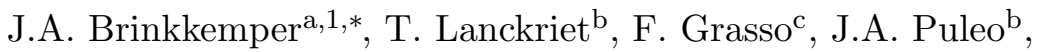 \\ B.G. Ruessink ${ }^{\mathrm{a}}$ \\ ${ }^{a}$ Institute for Marine and Atmospheric Research, Department of Physical Geography, \\ Faculty of Geosciences, Utrecht University, P.O. Box 80.115, 3508 TC Utrecht, \\ Netherlands \\ ${ }^{b}$ Center for Applied Coastal Research, Department of Civil and Environmental \\ Engineering, University of Delaware, Newark, DE 19716, United States \\ ${ }^{c}$ Ifremer - Dyneco/Physed, Centre de Bretagne, BP70, 29280 Plouzané, France
}

\begin{abstract}
Current coastal-evolution models generally lack the ability to accurately predict bed level change in shallow $(<\sim 2 \mathrm{~m})$ water, which is, at least partly, due to the preclusion of the effect of surface-induced turbulence on sand suspension and transport. As a first step to remedy this situation, we investigated the vertical structure of turbulence in the surf and swash zone using measurements collected under random shoaling and plunging waves on a steep (initially 1:15) field-scale sandy laboratory beach. Seaward of the swash zone, turbulence was measured with a vertical array of three Acoustic Doppler Velocimeters (ADVs), while in the swash zone two vertically spaced acoustic doppler velocimeter profilers (Vectrino profilers) were applied. The vertical turbulence structure evolves from bottom-dominated to approximately vertically uniform with an increase in the fraction of
\end{abstract}

\footnotetext{
*Corresponding author

Email address: j.a.brinkkemper@uu.nl (J.A. Brinkkemper)

${ }^{1}$ Phone: +31302532982 . Fax: +31302531145
} 
breaking waves to $\sim 50 \%$. In the swash zone, the turbulence is predominantly bottom-induced during the backwash and shows a homogeneous turbulence profile during uprush. We further find that the instantaneous turbulence kinetic energy is phase-coupled with the short-wave orbital motion under the plunging breakers, with higher levels shortly after the reversal from offshore to onshore motion (i.e. wavefront).

Keywords: turbulence, plunging breakers, swash, laboratory experiment

\section{Introduction}

Morphodynamic models can predict morphological change in the nearshore zone with reasonable accuracy, where the water depth exceeds $\sim 2 m$ and the morphology is approximately alongshore uniform (e.g. Kuriyama, 2012; Plant et al., 2004; Ruessink, 2005; Ruessink et al., 2007; Ruggiero et al., 2009; Walstra et al., 2012). There is, however, still a mismatch between predictions and observations for the inner surf and swash zones (e.g. Masselink and Puleo, 2006; Ruessink, 2005; Ruessink and Kuriyama, 2008). These zones are the connection for sand exchange between deeper water and the beach and are thus of high importance for the design of beach-restoration and nourishment projects. Most morphodynamic models calculate sediment transport solely with near-bed wave orbital motions (e.g. Bailard, 1981; Ribberink, 1998), lacking the influence of surface-induced turbulence which also plays a role in sand entrainment in the surf and swash zone (Aagaard and Hughes, 2010; Nadaoka et al., 1988; Voulgaris and Collins, 2000; Yoon and Cox, 2012). To improve the transport formulations for shallow water, a better understanding of the mechanisms involved in the suspension and trans- 
port of sand in the surf and swash zone is needed (e.g. Van Rijn et al., 2013). This paper presents a recently collected field-scale laboratory dataset and focuses on the vertical structure of turbulence in the surf and swash zone as a first step toward more accurate sand transport predictions in these zones.

The difference between the shoaling and the surf zone in terms of sediment suspension by turbulence is the presence of surface-induced turbulence in the surf zone (Thornton, 1979). At the sea surface, turbulence is generated by breaking waves and bores in horizontal and oblique vortices (Nadaoka et al., 1989; Zhang and Sunamura, 1990), able to travel downward to the bed and suspend sediment intermittently (Aagaard and Hughes, 2010; Nadaoka et al., 1988; Voulgaris and Collins, 2000; Yoon and Cox, 2012). As these vortices also keep sediment in suspension, the timing of these vortices in the wave phase determines whether vortices, and thus sediment, are transported in the landward or seaward direction by the wave orbital motion. The structure and intermittency of the generated turbulence are highly dependent on the breaker type (Zhang and Sunamura, 1990). The turbulence in spilling breakers is confined to the upper part of the water column due to the relatively small size of the generated eddies $(0.1-0.2 h$, where $h$ is the water depth) (Ting and Kirby, 1996), but turbulence spreads downwards in obliquely descending eddies behind the wave crest (Nadaoka et al., 1989). The amount of turbulence is fairly homogeneous over a wave cycle beneath spilling breakers and thus turbulence is generally transported in the seaward direction due to the longer duration of the offshore wave motion (Ting and Kirby, 1994). Turbulence beneath plunging breakers is characterized by downburst vortices generated by the impact of the overturning wave crest. 
This results in large mixing lengths and more homogeneous turbulence intensities in the vertical. The vortices were found around the breaking wave front and are thus correlated with onshore orbital motions, resulting in an onshore transport of turbulence beneath plunging breakers (e.g. Ting and Kirby, 1994, 1995). Recently, Aagaard and Hughes (2006) as well as Aagaard and Jensen (2013) found the largest sediment concentrations just after the onshore velocity maximum for plunging breakers in the field, suggesting the coupling between turbulence and suspension events and sediment transport by the wave orbital motion in the onshore direction. The sediment concentration beneath bores was much more homogeneous over time and no net wave-induced sediment transport was measured.

The change from near-bed orbital motion to surface-generated eddies as dominant sand stirring mechanism from the shoaling into the surf zone is also reflected in measured vertical profiles of wave-averaged turbulent kinetic energy $(k)$. Numerous smallscale laboratory experiments have been conducted with a fixed bed and regular breaking waves using laser Doppler anemometry (LDA, see Mocke (2001) for an overview) and more recently with particle image velocimetry (PIV) (e.g. Govender et al., 2011; Kimmoun and Branger, 2007; Sou et al., 2010). These methods provide detailed turbulence measurements in the cross-shore and vertical directions, while the alongshore component is often approximated assuming that turbulence beneath breaking waves is similar to plane wake flow (Svendsen, 1987). The vertical structure of turbulence was found to depend strongly on the wave-breaking type. 
Conditions with plunging breakers result in a relatively uniform turbulence profile, while spilling breakers show a strong increase of turbulent kinetic energy close to the water surface. Typical values for the Froude-scaled turbulent kinetic energy $(\sqrt{k / g h}$, where $g$ is the gravitational acceleration and $h$ is the water depth) below the wave trough level are between 0.03 and 0.07 for spilling breakers, and between 0.05 and 0.1 below plunging breakers (Mocke, 2001).

While these small-scale laboratory studies have provided substantial knowledge on turbulence beneath regular breaking waves on a fixed bed, it is uncertain how these measurements compare to field scale and irregular waves over a mobile bed. Scott et al. (2005) measured turbulence beneath regular and irregular breaking waves above a fixed bed in a large-scale flume and found a similar vertical and cross-shore structure of turbulence for both wave conditions, but the magnitude of the turbulent kinetic energy was up to five times larger beneath regular waves. The vertical structure and intensity (Froude-scaled turbulence between 0.02 and 0.06 at the bar crest) of turbulent kinetic energy measured during the experiments with identical random wave conditions but with a movable bed were similar to experiments with a fixed bed (Yoon and Cox, 2010). In these large-scale laboratory experiments, turbulence characteristics were measured using several vertical arrays of Acoustic Doppler Velocimeters (ADVs), offering some insight into their cross-shore structure. In general the tur- 
bulent kinetic energy is maximum at the location where most wave energy is dissipated by breaking, consistent with the dominance of surface-generated turbulence. In the field, however, a vertical profile of turbulence is often measured at a single cross-shore location because of logistical constrains (e.g. Feddersen et al., 2007; Ruessink, 2010). The time-variation in offshore wave conditions and tidal water level then results in measurements at different locations with respect to the breaker zone, but instruments at one cross-shore location inherently do not provide any information on the cross-shore variability of the turbulent structure. Field experiments show a dependency of the vertical turbulence structure on $H_{s} / h$ in the surf zone, where $H_{s}$ is the significant wave height. Surface-induced turbulence becomes increasingly important with higher relative wave height and is dominant in the inner surf zone (e.g. Grasso et al., 2012; Lanckriet and Puleo, 2013), where the majority of the waves have transformed into bores and ripples are generally absent. Measurements in natural surf zones indicate turbulence intensities increase towards the surface and towards the bed (Feddersen et al., 2007; Grasso et al., 2012), indicating that both surface-induced and bed-induced turbulence are important in the field. Grasso et al. (2012) hypothesised that the difference between field datasets in turbulence intensities in the lower part of the water column, and with laboratory measurements with a fixed bed, might be explained by differences in bed roughness (i.e. presence of ripples). On the whole, there is still substantial need 
for turbulence observations under natural conditions.

The turbulence in the swash zone can be advected from the surf zone as well as be generated locally. In comparison to the research conducted on the turbulence structure in the surf zone, the research on turbulence characteristics in the swash zone is still in its infancy, especially under natural conditions. As in the surf zone, turbulence can be generated at both the surface and the bottom by bores and bottom shear, respectively. During backwash, turbulence is dominantly generated by bottom shear (e.g. Cowen et al., 2003), but past studies are inconclusive on the shape of the dissipation profile and the dominant turbulence production mechanism during uprush. Petti and Longo (2001) observed $k$ profiles increasing upward in measurements on a small-scale, smooth 1:10 beach slope, indicating that surface processes were dominant. On a smallscale, smooth 1:20 beach slope, Sou et al. (2010) observed that bed shear was dominant in the swash zone but surface processes were dominant in the inner surf zone. O’Donoghue et al. (2010) observed depth-uniform dissipation profiles on a large-scale (in terms of velocities and run-up length), smooth 1:10 slope and bottom-dominated profiles on a rough (grain diameter of 5-6 mm) 1:10 slope. Lanckriet and Puleo (2013), however, observed surface-dominated dissipation profiles in the inner surf and swash zone on a dissipative (slope 1:45) beach under field conditions.

Although the vertical structure of turbulence in idealized laboratory surf and swash zones is well researched, simultaneous measurements of turbulence in both zones at field scale are scarce but necessary to make progress in our understanding of sediment 
transport in shallow water. This lack of data and process understanding was one of the reasons to carry out the second large-scale Barrier Dynamics Experiment (BARDEXII). BARDEXII was designed to improve understanding of sediment transport processes in the surf, swash and overwash zone (see also Masselink et al. (submitted)) of a medium-coarse grained sandy barrier. This paper focuses on the measured vertical structure of turbulence and its variability from the shoaling into the swash zone. The structure of the paper is as follows. In Section 2, we describe the experimental setup, initial data processing and the methods used to extract turbulence from the measured velocities. In Section 3 we discuss the vertical profiles of turbulence and its intra-wave variability in the shoaling, surf and swash zones. These results are discussed and compared with earlier observations in Section 4. Conclusions are provided in Section 5.

\section{Methods}

\subsection{BARDEXII}

The BARDEXII experiment was carried out in the Delta Flume in Vollenhove, The Netherlands, from May to July 2012. A 4.5 m high, 5 m wide and $75 \mathrm{~m}$ long sandy (median grain diameter $d_{50}=0.42 \mathrm{~mm}$ ) barrier was constructed in the central region of the flume, enabling a lagoon to be situated at its landward side. Initially, the profile contained an 1:15 slope from $x=49 \mathrm{~m}$ to $x=109 \mathrm{~m}$, where $x=0$ is at the wavemaker (Figure 1 ). Masselink et al. (submitted) describe the objectives and the experimental 
setup of the project. We now describe the conditions and instruments that are used here.

The experiment consisted of five test series (A-E) with a total of 19 distinct tests with different wave and water level conditions. Test series A focused on beach response to varying wave conditions and different lagoon levels; B on bar dynamics due to different water levels on the seaside of the barrier; $\mathrm{C}$ on beach response to varying wave conditions with a tide; $\mathrm{D}$ on identifying overtopping/overwash thresholds and E on barrier overwash. Table 1 provides an overview of the significant spectral wave height $H_{\mathrm{m} 0}$ and peak period $T_{p}$ near the wavemaker, and of the water level relative to the flume floor $\bar{\zeta}$. The wavemaker was forced with random waves with a JONSWAP spectrum. The test series were divided in runs with a length of 15-180 minutes. In between these runs the cross-shore bed profile was measured along the centerline of the flume with a mechanical bed profiler (cross-shore resolution of $\mathbf{0 . 0 1} \mathbf{~ m}$ ). Between several test series, a run with monochromatic waves and a run with bichromatic waves were additionally carried out.

\subsection{Instruments}

\subsubsection{Shoaling and surf zone}

Measurements seaward of the swash zone were collected at $x=65 \mathrm{~m}$ (Figure 1). Here, 3 sideways-oriented and vertically stacked Sontek Ocean ADVs were positioned (Figure 2a) to measure all three velocity components. The instruments were, together with a pressure transducer (PT), attached to a wall-mounted 
scaffolding rig (further referred to as surf rig) with around $2 \mathrm{~m}$ between the instruments and the nearest flume wall. The vertical position of the rig was manually adjustable, ensuring an equal height of the instruments above the bed at the start of each run (0.175, 0.435 and $0.7 \mathrm{~m}$ for ADV1-3 and $0.25 \mathrm{~m}$ for the PT). The timeseries of instantaneous pressure were converted to sea surface elevation using linear wave theory and processed into the values of the local waterdepth $h$ and high-frequency $(0.05<f<1 \mathbf{H z})$ wave height $H_{m 0}$. The lowermost ADV failed during series A1-A6, and was replaced by a Nortek ADV in series A7. The Sonteks operated at $10 \mathrm{~Hz}$ in bursts of 29 minutes and the Nortek operated continuously at $16 \mathrm{~Hz}$; the timeseries of the Nortek ADV were later downsampled spectrally to $10 \mathrm{~Hz}$ for consistency with the Sontek ADVs. All data were time-stamped by the rig's central data logging system.

\subsubsection{Swash zone}

Swash zone velocities were collected at the central swash zone measurement station $(x=89.6 \mathrm{~m}$, Figure 1$)$, the same location as the analysis of sediment transport partitioning by Puleo et al. (submitted). Two Nortek Vectrino-II profiling acoustic velocimeters were deployed here (Figure 2b), each recording a profile of all three velocity components with a resolution of $0.001 \mathrm{~m}$ over a range of $0.03 \mathrm{~m}$ at a $100 \mathrm{~Hz}$ sampling rate. Velocimeters were positioned with an alongshore spacing of $0.12 \mathrm{~m}$ and a vertical offset of $0.025 \mathrm{~m}-0.030 \mathrm{~m}$, resulting in a velocity profile from the bed up 
to $0.05 \mathrm{~m}$ above the bed. Additionally, three ARGUS-style cameras (Figure 2c) recorded images $(20 \mathrm{~Hz})$ of the wave field from the wavemaker into the swash zone. These observations were stored in timestacks as the cross-shore pixel intensity averaged over a 50 pixels wide 'alongshore' strip.

\subsection{Turbulence data processing}

\subsubsection{Shoaling and surf zone}

The velocity series were quality controlled and despiked based on the guidelines by Elgar et al. (2005) and Mori et al. (2007). Beam velocities were transformed into the ADV's orthogonal coordinate system, which was subsequently rotated into cross-shore $u$, 'alongshore' $v$ and vertical $w$ velocities. Positive $u$ is in the shoreward direction, positive $v$ into the sensor perpendicular to the flume and positive $w$ is upward. Further details on the quality control of the ADV measurements applied here are described in Ruessink (2010).

For each run, turbulence velocities $u^{\prime}, v^{\prime}$ and $w^{\prime}$ were estimated using the two-sensor filtering technique of Feddersen and Williams (2007), as modified by Gerbi et al. (2009). This method uses adaptive-filtered velocities from a vertically spaced sensor B to estimate the turbulence at sensor A, by subtracting coherent wave motions from the demeaned timeseries measured by sensor A. Here, sensor A and B can both be either ADV 1, 2 or 3 . Turbulent velocities at a specific location can be estimated in two ways, for example at ADV1 using series of either ADV2 or ADV3, denoted 1(2) and 1(3) henceforth. The vertical distance between sensor A and B must be large relative to the turbulent length scale, but small enough to ensure 
that wave velocities are correlated. This is increasingly complicated closer to the bed, where wave velocities are dampened (Yoon and Cox, 2010). The turbulent length scale is typically between $\sim 0.1-0.3 h$ beneath breaking waves (e.g. Feddersen, 2012; Govender et al., 2004; Pedersen et al., 1998; Sou et al., 2010). Turbulence velocities $u^{\prime}, v^{\prime}$ and $w^{\prime}$ were squared, and after subtracting the Doppler noise variance $(3-5 \mathrm{~Hz})$ from each component (Grasso and Ruessink, 2012; Scott et al., 2005), combined into the turbulent kinetic energy as

$$
k=0.5\left(\overline{u^{\prime 2}}+\overline{v^{\prime 2}}+\overline{w^{\prime 2}}\right)
$$

where the overline denotes the average over a run.

When experiments use regular wave series, it is common practice to extract the turbulence velocities by subtracting the ensemble average from the measured time series (Svendsen, 1987). The assumption is that the wave orbital motions are equal beneath each wave or wave group, but turbulence is random and is thus not included in the ensemble average. To investigate the accuracy of the two-sensor filtering technique and the difference between turbulence estimates using a large (e.g. 1(3)) and a small (e.g. 1(2)) instrument separation distance, $k$ estimated with both the two-sensor filtering technique and using the ensemble average are compared for a mono- and a bichromatic wave run with values for wave height and period similar to A7 (Table 1). Overall, values for $k$ derived with both techniques are of the same order and do show the same vertical structure (Figure 3), in agreement with Scott et al. (2005). For the bichromatic case, the estima- 
tions with more vertical distance, 1(3) and 3(1), show larger values than the estimations with less vertical distance, 1(2) and 3(2) (Figure 3b). This difference can be ascribed to wave bias included in the turbulence timeseries when the vertical distance between the sensors is larger (Yoon and Cox, 2010). Taking this into account, turbulence was extracted in the remainder of this study using the sensor combinations 1(2), 2(3) and 3(2). The vertical distance between instruments 1 and 2 is $0.26 \mathrm{~m}$, and between 2 and 3 is $0.265 \mathbf{~ m}$, which corresponds to a distance of $0.1-0.3 h$.

Despite the small vertical distance used in the adaptive filtering, wave bias may still be present in the turbulence time series (Feddersen and Williams, 2007). To further assess the quality of $u^{\prime}, v^{\prime}$ and $w^{\prime}$, the cospectra of $\overline{u^{\prime} w^{\prime}}$ and $\overline{v^{\prime} w^{\prime}}$ were used (Feddersen and Williams, 2007). The nondimensional cumulative cospectrum (ogive) of $\overline{u^{\prime} w^{\prime}}$ is defined as

$$
O g_{u^{\prime} w^{\prime}}(f)=\frac{\int^{f} C o_{u^{\prime} w^{\prime}}(\hat{f}) d \hat{f}}{\overline{u^{\prime} w^{\prime}}}
$$

where $C o_{u^{\prime} w^{\prime}}$ is the cospectrum of $u^{\prime} w^{\prime}$. The ogive of $v^{\prime} w^{\prime}$ is defined similarly. Ogive curves are expected to increase gradually from 0 to 1 , sharp increases or fluctuations indicate wave bias. In line with Ruessink (2010), this study rejects measurements where $O g(f)$ of both $u^{\prime} w^{\prime}$ and $v^{\prime} w^{\prime}$ was not in the range $-0.5<O g(f)<1.6$ for all frequencies. In total 35, 39 and 48 runs were selected for further analyses for ADV1, 2 and 3, respectively. For these runs also the turbulence dissipation, $\epsilon$, was estimated from the $1.5-3 \mathrm{~Hz}$ frequency range using the approach of Feddersen et al. (2007) and Gerbi et al. (2009). 


\subsubsection{Swash zone}

Instruments in the swash zone are not constantly submerged as in the surf zone. For this reason other methods are required to retrieve turbulence characteristics. We here limited ourselves to $\epsilon$, for which estimation approaches exist. Vertical $\epsilon$ profiles were calculated using the structure function method described by Pope (2000) and Lanckriet and Puleo (2013). In the inertial subrange, the structure function takes the form

$$
D(z, r, t)=C \epsilon(z, t)^{2 / 3} r^{2 / 3}
$$

where $C=2.0$ is an empirical constant (Pope, 2000). The second-order longitudinal structure function for the vertical velocity $w$ was calculated as

$$
D(z, r, t)=\left\langle\left\{w^{\prime}(z+r / 2, t)-w^{\prime}(z-r / 2, t)\right\}^{2}\right\rangle,
$$

where $w^{\prime}=\langle w\rangle-w$ is the fluctuating vertical velocity component, $z$ is the elevation within the velocity profile and $r$ is the separation distance. The structure function was then fitted to

$$
D(z, r, t)=N+A r^{2 / 3}
$$

where $N$ and $A$ are fitting parameters. $N$ is indicative of measurement noise and $A$ is a measure of the decorrelation of the velocity field with increasing separation distance due to turbulence (Wiles et al., 2006). The dissipation rate $\epsilon$ was then calculated as 


$$
\epsilon=\left(\frac{A}{C}\right)^{3 / 2}
$$

Velocimeters were only submerged for $\mathrm{O}(5 \mathrm{~s})$ during each swash event, see also Section 2.4. Due to the short duration of the swash events, a time averaging window of $1.5 \mathrm{~s}$ with $50 \%$ overlap between dissipation estimates was chosen to calculate the fluctuating velocity component and the structure function. A sensitivity analysis of the time averaging window length on dissipation rate estimates on a natural, dissipative beach showed that dissipation rate estimates were highly similar for window lengths ranging from $1.5 \mathrm{~s}$ to $3.5 \mathrm{~s}$ (Lanckriet and Puleo, 2013). The temporal evolution of the bed level was detected from the center beam reflection amplitude of the velocimeter bottom scan function, scanning at $2 \mathrm{~Hz}$. Vertical dissipation profiles were referenced to a time-varying vertical coordinate $z$ with datum $z^{\prime}=0$ at the bed level. For test series A8, the bed level fluctuated outside of the velocimeter profiling range during a large portion of the test series so that the bed level could not be defined; the analysis of turbulence dissipation rate profiles in the swash zone is therefore conducted only for series A2, A4 and A7.

\subsection{Experimental conditions}

\subsubsection{Morphology}

As described more extensively in Ruessink et al. (submitted), a sandbar developed near the outer surf zone during series A1 $(x \approx 69 \mathrm{~m})$, and remained approximately unaltered to the end of series A4. During the following series (A6-A8), low-steepness waves resulted in the onshore migra- 
tion and subsequent disappearance of the sandbar, and the development of a berm on the upper beach. During tests B and C, a horizontal platform formed between $x \approx 70-85 \mathrm{~m}$, while the remainder of the profile was fairly stable. The overwash during series D and E resulted in barrier destruction.

\subsubsection{Ripples}

The bed state, i.e. ripple characteristics, at the location of the surf rig was determined using the measurements from the mechanical bed profiler. As described in detail in Ruessink et al. (submitted), for each surveyed bed profile the small-scale wave ripples were separated from the large-scale bar and berm using a scale-controlled interpolator (Plant et al., 2002). A $10 \mathrm{~m}$ long stretch of ripple data, centered around the surf rig, was processed with the approach of Masselink et al. (2007) into an estimate of ripple length and height for each survey. Results for a shorter stretch $(5 \mathrm{~m})$ were similar but more scattered. The ripple height ranged from $0.02-0.16 \mathrm{~m}$, where the highest ripples were found where the relative wave height was in the range $0.45-0.65$ (Figure 4a). The ripple length increased linearly with relative wave height $\left(H_{m 0} / h\right.$, Figure $\left.4 \mathrm{~b}\right)$. Ripple steepness ranged from $\sim 0.12$ for low relative wave height to $\sim 0.02$ under breaking waves (Figure $4 \mathrm{c}$ ). Observations with a $3 \mathrm{D}$ profiling sonar, collected seaward of the surf rig at $x=63.1 \mathrm{~m}$, illustrate that the ripples were strongly threedimensional during series $\mathrm{A}$ and $\mathrm{B}$ and more two-dimensional during $\mathbf{D}$ and $\mathbf{E}$. In the swash zone the bed remained flat (no ripples). 


\subsubsection{Hydrodynamic zones}

The different offshore wave and water level conditions (Table 1) resulted in a variety of wave conditions at the surf rig. We divided these conditions in three classes: (1) pre-shoaling and shoaling without wave breaking, (2) shoaling with occasional wave breaking, and (3) breaking (surf zone). The criteria to divide the test runs into these classes were based on $H_{m 0} / h$, the wave shape and the fraction of broken waves, $Q_{b}$. As waves propagate into shallower water, their shape changes from sinusoidal to peaked (skewness) and pitched forward (asymmetry). As such, the skewness and asymmetry are valuable parameters to determine the cross-shore position in terms of hydrodynamic processes. The skewness and asymmetry were calculated as:

$$
\begin{aligned}
& S k=\frac{\left\langle(\eta-\langle\eta\rangle)^{3}\right\rangle}{\left\langle(\eta-\langle\eta\rangle)^{2}\right\rangle^{3 / 2}}, \\
& A s=\frac{\left\langle H^{3}(\eta-\langle\eta\rangle)\right\rangle}{\left\langle(\eta-\langle\eta\rangle)^{2}\right\rangle^{3 / 2}},
\end{aligned}
$$

where $\eta$ is the sea surface timeseries and $H$ is the Hilbert transform. At the surf rig, $S k$ ranged from 0 to 1.0 and $A s$ from 0 to -1.5 (Figure 5a). These values are larger than those measured during comparable conditions in the field (e.g. Grasso et al., 2012; Ruessink et al., 2012b), explained by the lack of directional spread and therefore stronger energy-transfers to higher harmonics in a laboratory flume (e.g. Grasso et al., 2011). The fraction of broken waves $\left(Q_{b}\right)$ at the location of the surf rig was determined by marking wave breaking locations manually on the video timestacks (Figure 6). The 
$Q_{b}$ at the rig was calculated as the amount of waves breaking seaward of the rig divided by the total amount of waves, resulting in $Q_{b}$ ranging from 0 to 0.48 (Figure $5 \mathrm{~b}$ ). Both the wave shape and $Q_{b}$ scale with $H_{\mathrm{m} 0} / h$ (Figure 5), which makes this a suitable parameter to classify the runs.

The observations under pre-shoaling and shoaling waves were recognized as where the skewness and asymmetry are increasing with $H_{\mathrm{m} 0} / h$, but $Q_{b}$ is still zero. This is valid for $H_{\mathrm{m} 0} / h<0.475$ (Figure 5 ). $S k$ remains constant for $H_{\mathrm{m} 0} / h>0.475$, while $|A s|$ increases linearly. The test series with shoaling waves and occasional wave breaking at the surf rig is recognized for $|A s|<S k$, while $Q_{b}$ is below 0.15 . This is valid for $0.475<H_{\mathrm{m} 0} / h<0.675$. Test series were classified as the surf zone when $|A s|>S k$, valid for $H_{\mathrm{m} 0} / h>0.675$. The number of runs in these classes is $15(18,20), 7(16,21)$ and $13(5,7)$ for ADV1 (ADV2, ADV3), respectively. The vast majority of waves were observed to break as plunging breakers. An occasional wave plunged immediately from the wavemaker and propagated as a bore through the entire flume.

The swash zone velocimeters were at the correct cross-shore and vertical position to measure swash dynamics during conditions A2, A4 and A7. The relative cross-shore position of the instruments in the swash zone was determined from the timestacks (Figure 7). Hughes and Moseley (2007) divided the swash zone into two hydrokinematic regions: the outer swash zone, where swash-swash interactions occur, and the inner swash zone, which consists of pure swash motion (free from interaction with subsequent waves). Velocimeters in this study were located near the transition between the inner and outer swash zone because the majority of swash events occurred as pure 
swash motion, but swash-swash interactions still occurred occasionally (e.g. Figure $7, t=45 \mathrm{~s}$ ). Furthermore, visual observations, recorded by a handheld digital camera, showed that waves initially propagated as turbulenceand bubble-producing bores. At a certain point in the swash zone, turbulence and bubble production at the bore tip appeared to cease and the uprush continued as a smoother swash lens until the runup limit, with remnant bubbles visible at the water surface. This transition from a turbulent bore to a smooth swash lens is commonly visible on natural beaches. The cross-shore pixel intensity timestack, collected during run 5 of test series A2, shows additional evidence for this (Figure 7). The cross-shore position of the velocimeters is indicated by the white vertical line. During certain bore runup events, an abrupt transition is visible in the pixel intensity (indicative of bubble content) near the runup tip as the swash event transitioned from a bubble-producing bore to a smoother swash lens. During some swash events, e.g. at $t=7 \mathrm{~s}$ and $t=22 \mathrm{~s}$, the swash event has become a smooth swash lens by the time it reaches the velocimeters. During other events, e.g. at $t=29 \mathrm{~s}, t=36 \mathrm{~s}$, and $t=44 \mathrm{~s}$, the bore tip was still laden with bubbles as it passed the velocimeters.

\section{Results}

\subsection{Shoaling and surf zone}

Class-averaged turbulence characteristics are analysed with both the Froude-scaled turbulent kinetic energy $\sqrt{k / g h}$ and the turbulence dissipation $\epsilon$ (Figures $\mathbf{8 a}, \mathbf{b})$. The magnitude of $\sqrt{k / g h}$ increases with relative wave height (Figure 8a). The two classes with non-breaking 
and occasional-breaking conditions show an increase in $\sqrt{k / g h}$ towards the bed. This can be attributed to bed-generated turbulence and is certainly enhanced by the observed ripples (Section 2.4.2). It must be noted, however, that the three ADVs were all located in the lower half $(0.1-0.5 h)$ of the water column for these conditions and that the potential near-surface increase in $\sqrt{k / g h}$ in the class with occasional wave breaking may have been missed. The vertical turbulence profile in the surf zone shows larger values throughout the water column and becomes relatively uniform. The same conclusions can be drawn from vertical profiles of $\epsilon$ (Figure $8 \mathrm{~b}$ ) and illustrates that $k$ and $\epsilon$ can be used interchangeably to study the vertical turbulence profile.

The cross-shore transport of turbulence by wave velocities relates to sediment transport as turbulent vortices keep sand in suspension. The intrawave variability in $\sqrt{k / g h}$ indicates whether the majority of turbulence is transported by waves in the onshore or the offshore direction. To investigate intra-wave variability for both short waves and infragravity waves, the timeseries of cross-shore velocity $(u)$ were frequency filtered for shortwave $\left(u_{h f}, 0.05<f<0.5 \mathrm{~Hz}\right)$ and infragravity-wave motion $\left(u_{l f}, 0.005\right.$ $<f<0.05 \mathrm{~Hz}$ ). The instantaneous wave phase was calculated for both timeseries using the Hilbert transform, and $\sqrt{k /(g h)}$ was then averaged into $0.2 \pi$ wide bins. These phase-averaged quantities were grouped and averaged based on $H_{m 0} / h$, in the classes non-breaking $\left(H_{\mathrm{m} 0} / h<0.475\right)$ and breaking $\left(H_{\mathrm{m} 0} / h>0.675\right)$. Turbulence intensities beneath non-breaking waves are largest close to the bed and decrease rapidly towards the water surface during all wave phases (Figure 9a). The largest values for $\sqrt{k /(g h)}$ are present 
after reversal from offshore to onshore flow, when the orbital velocity is in the onshore direction. This intra-wave variability is probably caused by vortex shedding (van der Werf et al., 2007), as ripples with a steepness up to 0.12 were observed (Section 2.4.2). When waves are breaking, $\sqrt{k /(g h)}$ is larger throughout the water column during all phases (Figure 9b), indicating a large degree of vertical mixing. Near the surface $(z \sim 0.7 h), \sqrt{k /(g h)}$ is largest during flow reversal from offshore to onshore $u_{h f}$, while near the bottom, $\sqrt{k /(g h)}$ is largest when $u_{h f}$ is maximum onshore. This phase-lag between turbulence near the surface and near the bottom could indicate downward transport of surface-induced turbulence, although the position of the peak value measured by the middle ADV suggests a more complicated situation. The peak in turbulence near the water surface at $\varphi /(2 \pi) \approx 0.5$ indicates that the plunging jet of the breaking waves injects turbulence at the wave front, similar to observations beneath regular plunging waves (Ting and Kirby, 1995).

Beneath both non-breaking and breaking waves, $\sqrt{k /(g h)}$ is also modulated on an infragravity time scale (Figures 9c and d), with large $\sqrt{k /(g h)}$ when $u_{l f}$ is in the offshore direction. This phase-coupling can be explained by the presence of the highest short-waves in the trough of the infragravity waves. Beneath non-breaking waves this means larger wave-orbital velocities and presumably stronger vortex shedding from the ripples. The time series with breaking waves were collected in the outer surf zone, where only the highest waves break. At the location of the rig, approximately two-third of the broken waves were observed while $u_{l f}$ was in the offshore direction, giving rise to the observed infragravity modulation of $\sqrt{k /(g h)}$. 
Returning to Figure 8, the vertical turbulence profile was also analysed with the time-averaged vertical turbulence flux, $\overline{k^{\prime} w^{\prime}}$ (Figures $8 \mathrm{c}$ and d). Negative (positive) $\overline{k^{\prime} w^{\prime}}$ signify the majority of the turbulence events travelling downward (upward). These directions indicate whether turbulence is dominantly surface-generated (downward) or bed-generated (upward). The dominance of bed-generated turbulence for non-breaking and occasional breaking waves is confirmed by positive $\overline{k^{\prime} w^{\prime}}$ close to the bed (Figure 8c). The class with occasional wave breaking additionally shows a negative vertical turbulence flux near the surface, illustrating the downward flux of turbulence by the plunging breakers in these timeseries. The vertical profile and magnitude of the turbulence flux of this class is similar to field observations above a rippled bed described in Grasso and Ruessink (2012). Negative $\overline{k^{\prime} w^{\prime}}$ in the surf zone (Figure 8d) suggests downward travelling turbulence as dominant close to the bed, thus the large $\sqrt{k /(g h)}$ values observed close to the bed are not necessarily related to bed-induced turbulence. Although $\overline{k^{\prime} w^{\prime}}$ values are small in the surf zone in the upper part of the water column (Figure 8d), large instantaneous upward and downward turbulent fluxes were measured. This might be attributed to the presence of horizontal vortices in the upper part of the water column beneath plunging breakers (Zhang and Sunamura, 1990). The horizontal vortices may result in large instantaneous turbulence fluxes but cancel out in a time-average sense. 


\subsection{Swash zone}

Vertical dissipation profile measurements in the swash zone were binned (bin width 0.5s) and averaged according to the cross-shore velocity $u$ at the center bin of the upper velocimeter profile (nominally at $0.04 \mathrm{~m}$ above the bed), similar to the phase space averaging conducted by Foster et al. (2006), Lanckriet and Puleo (2013) and Puleo et al. (2003). Velocity time series during swash events exhibited a sawtooth shape with a roughly constant, offshore-directed acceleration that is characteristic for swash motions on a steep beach (Hughes and Baldock, 2004). The dissipation profiles were therefore not binned according to cross-shore acceleration since acceleration values were fairly uniform across the dataset. The results are not sensitive to a reduction in the velocity bin width to $0.25 \mathrm{~s}$.

Bin-averaged dissipation rate profiles for test series A2, A4 and A7 are displayed in Figure 10. Dissipation profiles for each velocity bin were highly similar in both shape and magnitude across the three test series, with mean dissipation rates for series A2, A4 and A7 at $1.9 \cdot 10^{-3} \mathrm{~m}^{2} / \mathrm{s}^{3}, 1.8 \cdot 10^{-3} \mathrm{~m}^{2} / \mathrm{s}^{3}$ and $2.1 \cdot 10^{-3} \mathrm{~m}^{2} / \mathrm{s}^{3}$, respectively. During the backwash (Figure 10, left two columns), dissipation rates were increasing toward the bottom, indicating that, in agreement with previous measurements (Lanckriet and Puleo, 2013; O'Donoghue et al., 2010; Petti and Longo, 2001; Sou et al., 2010), bed shear was the leading turbulence production mechanism. Limited turbulence dissipation data is available from the uprush phase (Figure 10, right column) due to the short durations of swash events $[\mathrm{O}(5 \mathrm{~s})$ at the instrument location] and the fact that the acoustic velocimeters did not obtain valid velocity data immediately upon bore arrival when they were hindered by bore-generated 
bubbles. The limited uprush data suggest that dissipation rate profiles were roughly depth-uniform or slightly increased near the bottom during the uprush.

\section{Discussion}

\subsection{Shoaling and surf zone}

The range in $\sqrt{k / g h}$ observed in the surf zone $(0.02-0.06)$ agrees with earlier large-scale experiments with irregular plunging waves (Yoon and Cox, 2010), although $\sqrt{k / g h}$ close to the bed is larger in our observations. The latter is presumably related to the waveinduced ripples observed here (Figure 4), while flat-bed conditions presumably dominated in the experiment of Yoon and Cox (2010) given the smaller grain size. The observed Froude-scaled turbulence is larger than found during field observations with both plunging breakers and bores (0.02-0.04, Ruessink (2010)), which might depend on wave conditions and the cross-shore location of the rig, and is low in comparison with regular plunging waves in the laboratory (0.06-0.12, Mocke (2001)). Our dataset lacks, however, observations with $Q_{b}>0.5$. It is expected that $k$ near the water surface further increases and $k$ near the bed becomes less important as $Q_{b}$ increases and the ripple steepness reduces.

The direction of turbulence transport by infragravity waves may depend on the horizontal location in the surf zone. Ting (2001, 2002) measured a net offshore directed transport by infragravity waves beneath spilling breakers in the outer surf zone. 
This reversed to the onshore direction in the inner surf zone, where short-waves are depth-saturated and can only reach shallower water on the crest of infragravity waves (e.g. Janssen et al., 2003; Tissier et al., 2013). Our dataset lacks observations in the inner surf zone and we cannot confirm the change in the direction of turbulence transport induced by infragravity waves.

In many small-scale experiments (e.g. Govender et al., 2011; Henriquez et al., 2014; Kimmoun and Branger, 2007; Sou et al., 2010; Ting and Kirby, 1994, 1995), turbulence is measured in high detail in two directions, $u^{\prime}$ and $w^{\prime}$. To account for the lack of having $v^{\prime}$ measurements in the total turbulent kinetic energy, $k$ is often estimated as $k=1.33 k^{*}$, with $k^{*}=0.5\left(\left\langle u^{\prime 2}\right\rangle+\left\langle w^{\prime 2}\right\rangle\right)$. The ratio between $k$ and $k^{*}$ is based on the assumption of plane wake turbulence in the surf zone, as proposed by Svendsen (1987), for which the ratio between $\left\langle u^{\prime 2}\right\rangle:\left\langle v^{\prime 2}\right\rangle:\left\langle w^{\prime 2}\right\rangle$ is $0.42: 0.26: 0.32$. Our observations are compared with these ratios in Figure 11. Observations are close to $k=1.33 k^{*}$ and thus support the assumption of plane wake turbulence in the surf zone. The ratios between the different turbulence components, however, differ from the values for plane wake turbulence with an increasing relative wave height. The cross-shore component of the turbulence, $\left\langle u^{\prime 2}\right\rangle / 2 k$, increases with $H_{m 0} / h$ and is particularly larger than the plane wake value in the surf zone $\left(H_{m 0} / h>0.675\right)$. For example for $0.7<H_{m 0} / h<0.9,\left\langle u^{\prime 2}\right\rangle:\left\langle v^{\prime 2}\right\rangle$ : $\left\langle w^{\prime 2}\right\rangle$ is $0.71: 0.12: 0.17$.

Ruessink (2010) also described the deviation from plane wake turbulence of observations during field campaigns at Truc Vert Beach (beach slope 1:40, 
France) in 2008 and at Ameland (beach slope 1:80, The Netherlands) in 2010 (Ruessink et al., 2012a); both datasets are added to Figure 11. For the field datasets, the ratio $k / k^{*}$ is about 1.6 , due to the higher importance of $v^{\prime}$ (Figure 11c). While the Ameland observations show weak correlation between $\left\langle v^{\prime 2}\right\rangle / 2 k$ and the mean alongshore current $(\bar{V})$, this does not explain the difference with plane wake turbulence. It seems the plane wake assumption holds for turbulence beneath shoaling and occasional breaking waves in a laboratory flume, but not for field observations. In the field, the longshore turbulence component might be enhanced by wave directional spreading. The difference between the datasets can also be caused (or enhanced) by the breaker type and its associated orientation of the turbulent vortices. The Ameland dataset consisted of spilling breakers, Truc Vert of both plunging breakers and bores, and BARDEXII of plunging breakers only. Beneath plunging breakers, the turbulence is organized in vortices with an alongshore rotation axes, enhancing $u^{\prime}$ and limiting $v^{\prime}$ (Nadaoka et al., 1989; Zhang and Sunamura, 1990), whereas beneath spilling breakers mainly oblique descending eddies are present with turbulence in all axes. This might explain (part of) the difference in $\left\langle v^{\prime 2}\right\rangle / 2 k$ between the different datasets, and the increase in $\left\langle u^{\prime 2}\right\rangle / 2 k$ with the fraction of breaking waves in the BARDEXII and Truc Vert datasets. The vertical turbulence component is in the same range for all datasets and is constant with $H_{m 0} / h$.

\subsection{Swash zone}

In this study, only limited measurements were obtained during the uprush but data show a roughly depth-uniform dissipation profile across the 
lower $0.05 \mathrm{~m}$ of the water column with a slight increase toward the bottom, indicating that bed-generated turbulence was important, if not dominant, during the uprush. It is noted, however, that only the lowest $0.05 \mathrm{~m}$ of the typical 0.2-0.3 $\mathrm{m}$ high uprush events were sampled here and that dissipation rates may have increased higher in the water column due to surface processes.

The mixed observations on whether surface or bottom-generated turbulence is dominant during the uprush may be explained by the location of the observations in the swash zone. In the lower swash zone, where swash runup occurs as a turbulent bore, turbulence production during the uprush is dominated by surface processes. In the upper swash zone, where the runup occurs as a smooth lens, turbulence production during the uprush is dominated by bottom shear. Under irregular wave forcing, the location of the transition point varies from wave to wave but may be influenced by swashswash interaction since surface turbulence production is certainly significant during bore-backwash interaction (e.g. Sou and Yeh, 2011), and the transition to a smooth swash lens often only occurs after the preceding backwash is fully completed. This mechanism would explain why past measurements taken near the seaward edge of the swash zone (e.g. Lanckriet and Puleo, 2013; Petti and Longo, 2001) found surface-dominated dissipation and $k$ profiles, while measurements taken further landward (e.g. Sou et al., 2010) displayed a bottom-dominated dissipation profile. O'Donoghue et al. (2010) measured uprush $k$ profiles at three locations in the swash zone, with $k$ profiles becoming more bottom-dominated in the landward direction. Our measurements were taken in the transition between the upper swash and 
the lower swash zone (see Section 2.4.3), and thus $k$ is homogeneous in the vertical. The transition from surface-dominated turbulence (uprush mainly as turbulent bores) to bed-dominated turbulence (uprush mainly as smooth swash lenses) during the uprush phase defines a new boundary between the lower and upper swash zone.

\section{Conclusions}

The vertical turbulence structure in the surf and swash zone of a fieldscale laboratory beach was studied. The cross-shore variation in the vertical structure provides insight into the importance of surface-induced turbulence, relative to bed-induced turbulence, in the different hydrodynamic zones. Seaward of the surf zone, the turbulence structure was dominated by bedinduced turbulence. The Froude-scaled turbulence was largest close to the bed during flow reversal of the wave orbital motion from negative to positive, possibly explained by the shedding of turbulent vortices by vortex ripples during flow reversal. In the surf zone, Froude-scaled turbulence was largest beneath the front of the waves, where the plunging jets of the breaking waves inject turbulence into the water column. In addition, for both nonbreaking and breaking waves, Froude-scaled turbulence was modulated on the group scale, with largest values when $u_{l f}$ was in the offshore direction. Turbulence is both generated at the surface and at the bed, but surfaceinduced turbulence is of increasing importance with the fraction of breaking waves. A location dependency of the vertical structure of turbulence is also suggested by our observations in the swash zone. Typically, surfaceinduced turbulence dominates during uprush and bed-induced turbulence 
during backwash, but in the upper-swash the uprush occurs as a smooth lens resulting in less surface-induced turbulence. Video observations show that our swash measurements were indeed collected at the transition between the lower and upper swash, resulting in a roughly uniform turbulence structure in the vertical during uprush.

\section{Acknowledgements}

We would like to acknowledge the Delta Flume staff, the Utrecht technicians, and Daan Wesselman and Winnie de Winter for their assistance during the experiment. JB and GR were funded by the Dutch Technology Foundation STW, which is part of the Netherlands Organisation for Scientific Research (NWO), and which is partly funded by the Ministry of Economic Affairs (project number 12397). JP and TL were funded by the National Science Foundation (NSF; OCE-0845004) and the University of Delaware. JP was additionally funded by the US/UK Fulbright commission and NSF (OCE-13322703). The work described in this publication was supported by the European Community's 7th Framework Programme through the grant to the budget of the Integrating Activity HYDRALAB IV, contract no. 261520. Finally, we thank the reviewers for their careful reading of the manuscript and their thought provoking comments. 


\section{References}

Aagaard, T., Hughes, M. G., 2006. Sediment suspension and turbulence in the swash zone of dissipative beaches. Marine Geology 228, 117-135.

Aagaard, T., Hughes, M. G., 2010. Breaker turbulence and sediment suspension in the surf zone. Marine Geology 271, 250-259.

Aagaard, T., Jensen, S. G., 2013. Sediment concentration and vertical mixing under breaking waves. Marine Geology 336, 146-159.

Bailard, J. A., 1981. An energetics total load sediment transport model for a plane sloping beach. Journal of Geophysical Research 86, 10938-10954.

Cowen, E. A., Sou, I. M., Liu, P. L. F., Raubenheimer, B., 2003. Particle image velocimetry measurements within a laboratory-generated swash zone. Journal of Engineering Mechanics 129, 1119-1129.

Elgar, S., Raubenheimer, B., Guza, R. T., 2005. Quality control of acoustic doppler velocimeter data in the surfzone. Measurement Science and Technology 16, 1889-1893.

Feddersen, F., 2012. Scaling surf zone turbulence. Geophysical Research Letters 39, L18613, doi:10.1029/2012GL052970.

Feddersen, F., Trowbridge, J. H., Williams, A. J., 2007. Vertical structure of dissipation in the nearshore. Journal of Physical Oceanography 37, 17641777. 
Feddersen, F., Williams, A. J., 2007. Direct estimation of the reynolds stress vertical structure in the nearshore. Journal of Atmospheric and Oceanic Technology 24, 102-116.

Foster, D. L., Beach, R. A., Holman, R. A., 2006. Turbulence observations of the nearshore wave bottom boundary layer. Journal of Geophysical Research 111, C04011, doi:10.1029/2004JC002838.

Gerbi, G. P., Trowbridge, J. H., Terray, E. A., Plueddemann, A. J., Kukulka, T., 2009. Observations of turbulence in the ocean surface boundary layer: Energetics and transport. Journal of Physical Oceanography 39, 10771096.

Govender, K., Michallet, H., Alport, M. J., 2011. DCIV measurements of flow fields and turbulence in waves breaking over a bar. European Journal of Mechanics, B/Fluids 30, 616-623.

Govender, K., Mocke, G. P., Alport, M. J., 2004. Dissipation of isotropic turbulence and length-scale measurements through the wave roller in laboratory spilling waves. Journal of Geophysical Research 109, C08018, doi:10.1029/2003JC002233.

Grasso, F., Castelle, B., Ruessink, B. G., 2012. Turbulence dissipation under breaking waves and bores in a natural surf zone. Continental Shelf Research 43, 133-141.

Grasso, F., Michallet, H., Barthlemy, E., 2011. Sediment transport associated with morphological beach changes forced by irregular asym- 
metric, skewed waves. Journal of Geophysical Research 116, C03020, doi:10.1029/2010JC006550.

Grasso, F., Ruessink, B. G., 2012. Turbulent viscosity in natural surf zones. Geophysical Research Letters 39, L23603, doi:10.1029/2012GL054135.

Henriquez, M., Reniers, A. J. H. M., Ruessink, B. G., Stive, M. J. F., 2014. Piv measurements of the bottom boundary layer under nonlinear surface waves. Coastal Engineering 94, 33-46.

Hughes, M. G., Baldock, T. E., 2004. Eulerian flow velocities in the swash zone: Field data and model predictions. Journal of Geophysical Research 109, C08009, doi:10.1029/2003JC002213.

Hughes, M. G., Moseley, A. S., 2007. Hydrokinematic regions within the swash zone. Continental Shelf Research 27, 2000-2013.

Janssen, T. T., Battjes, J. A., van Dongeren, A. R., 2003. Long waves induced by short-wave groups over a sloping bottom. Journal of Geophysical Research 108, 3252, doi:10.1029/2002JC001515.

Kimmoun, O., Branger, H., 2007. A particle image velocimetry investigation on laboratory surf-zone breaking waves over a sloping beach. Journal of Fluid Mechanics 588, 353-397.

Kuriyama, Y., 2012. Process-based one-dimensional model for cyclic longshore bar evolution. Coastal Engineering 62, 48-61.

Lanckriet, T., Puleo, J. A., 2013. Near-bed turbulence dissipation measure- 
ments in the inner surf and swash zone. Journal of Geophysical Research 118, 6634-6647, doi:10.1002/2013JC009251.

Masselink, G., Austin, M. J., O’Hare, T. J., Russell, P. E., 2007. Geometry and dynamics or wave ripples in the nearshore zone of a coarse sandy beach. Journal of Geophysical Research 112, C10022, doi:10.1029/2006JC003839.

Masselink, G., Puleo, J. A., 2006. Swash-zone morphodynamics. Continental Shelf Research 26, $661-680$.

Masselink, G., Ruju, A., Conley, D., Turner, I., Ruessink, G., Matias, A., Thompson, C., Castelle, B., Wolters, G., submitted. Large-scale barrier dynamics experiment II (BARDEX II): experimental design, instrumentation, test programme and data set. Coastal Engineering.

Mocke, G. P., 2001. Structure and modeling of surf zone turbulence due to wave breaking. Journal of Geophysical Research 106, 17039-17057.

Mori, N., Suzuki, T., Kakuno, S., 2007. Noise of acoustic doppler velocimeter data in bubbly flows. Journal of Engineering Mechanics 133, 122-125.

Nadaoka, K., Hino, M., Koyano, Y., 1989. Structure of the turbulent flow field under breaking waves in the surf zone. Journal of Fluid Mechanics 204, 359-387.

Nadaoka, K., Ueno, S., Igarashi, T., 1988. Sediment suspension due to large scale eddies in the surf zone. In: Proceedings of the 21st International 
Conference on Coastal Engineering. American Society of Civil Engineering, New York, NY, 1646-1660.

O’Donoghue, T., Pokrajac, D., Hondebrink, L., 2010. Laboratory and numerical study of dambreak-generated swash on impermeable slopes. Coastal Engineering 57, 513-530.

Pedersen, C., Deigaard, R., Sutherland, J., 1998. Measurements of the vertical correlation in turbulence under broken waves. Coastal Engineering $35,231-249$.

Petti, M., Longo, S., 2001. Turbulence experiments in the swash zone. Coastal Engineering 43, 1-24.

Plant, N. G., Holland, K. T., Puleo, J. A., 2002. Analysis of the scale of errors in nearshore bathymetric data. Marine Geology 191, 71-86.

Plant, N. G., Holland, K. T., Puleo, J. A., Gallagher, E. L., 2004. Prediction skill of nearshore profile evolution models. Journal of Geophysical Research 109, C01006, doi:10.1029/2003JC001995.

Pope, S. B., 2000. Turbulent flows. Cambridge university press.

Puleo, J., Lanckriet, T., Conley, D., Foster, D., submitted. Sediment transport partitioning in the swash zone of a large-scale laboratory beach. Coastal Engineering.

Puleo, J. A., Holland, K. T., Plant, N. G., Slinn, D. N., Hanes, D. M., 2003. Fluid acceleration effects on suspended sediment transport in the swash zone. Journal of Geophysical Research 108, 3350. 
Ribberink, J. S., 1998. Bed-load transport for steady flows and unsteady oscillatory flows. Coastal Engineering 34, 59-82.

Ruessink, B. G., 2005. Predictive uncertainty of a nearshore bed evolution model. Continental Shelf Research 25, 1053-1069.

Ruessink, B. G., 2010. Observations of turbulence within a natural surf zone. Journal of Physical Oceanography 40, 2696-2712.

Ruessink, B. G., Blenkinsopp, C., Brinkkemper, J. A., Castelle, B., Durbarbier, B., Grasso, F., Puleo, J. A., Lanckriet, T., Masselink, G., submitted. Sandbar and beachface evolution on a prototype coarse-grained sandy barrier. Coastal Engineering.

Ruessink, B. G., Boers, M., van Geer, P. F. C., de Bakker, A. T. M., Pieterse, A., Grasso, F., de Winter, R. C., 2012a. Towards a process-based model to predict dune erosion along the dutch wadden coast. Netherlands Journal of Geosciences-Geologie en Mijnbouw 91, 357-372.

Ruessink, B. G., Kuriyama, Y., 2008. Numerical predictability experiments of cross-shore sandbar migration. Geophysical Research Letters 35, L01603, doi:10.1029/2007GL032530.

Ruessink, B. G., Kuriyama, Y., Reniers, A. J. H. M., Roelvink, J. A., Walstra, D. J. R., 2007. Modeling cross-shore sandbar behavior on the timescale of weeks. Journal of Geophysical Research 112, F03010, 10.1029/2006JF000730.

Ruessink, B. G., Ramaekers, G., van Rijn, L. C., 2012b. On the parame- 
terization of the free-stream non-linear wave orbital motion in nearshore morphodynamic models. Coastal Engineering 65, $56-63$.

Ruggiero, P., Walstra, D. J. R., Gelfenbaum, G., van Ormondt, M., 2009. Seasonal-scale nearshore morphological evolution: Field observations and numerical modeling. Coastal Engineering 56, 1153-1172.

Scott, C. P., Cox, D. T., Maddox, T. B., Long, J. W., 2005. Large-scale laboratory observations of turbulence on a fixed barred beach. Measurement Science and Technology 16, 1903-1912.

Sou, I. M., Cowen, E. A., Liu, P. L.-F., 2010. Evolution of the turbulence structure in the surf and swash zones. Journal of Fluid Mechanics 644, $193-216$.

Sou, I. M., Yeh, H., 2011. Laboratory study of the cross-shore flow structure in the surf and swash zones. Journal of Geophysical Research 116, C03002, doi:10.1029/2010JC006700.

Svendsen, I. A., 1987. Analysis of surf zone turbulence. Journal of Geophysical Research 92, 5115-5124.

Thornton, E. B., 1979. Energetics of breaking waves within the surf zone. Journal of Geophysical Research 84, 4931-4938.

Ting, F. C. K., 2001. Laboratory study of wave and turbulence velocities in a broad-banded irregular wave surf zone. Coastal Engineering 43, 183-208.

Ting, F. C. K., 2002. Laboratory study of wave and turbulence character- 
istics in narrow-band irregular breaking waves. Coastal Engineering 46, $291-313$.

Ting, F. C. K., Kirby, J. T., 1994. Observation of undertow and turbulence in a laboratory surf zone. Coastal Engineering 24, 51-80.

Ting, F. C. K., Kirby, J. T., 1995. Dynamics of surf-zone turbulence in a strong plunging breaker. Coastal Engineering 24, 177-204.

Ting, F. C. K., Kirby, J. T., 1996. Dynamics of surf-zone turbulence in a spilling breaker. Coastal Engineering 27, 131-160.

Tissier, M., Almar, R., Bonneton, P., Michallet, H., de Bakker, A., Ruessink, G., 2013. Role of short and long-wave interaction on wave celerity in the surf zone of a low-sloping beach. Proc. Seventh Int. Conf. on Coastal Dynamics, Bordeaux, France, Bordeaux University, 1677-1686.

van der Werf, J. J., Doucette, J. S., O’Donoghue, T., Ribberink, J. S., 2007. Detailed measurements of velocities and suspended sand concentrations over full-scale ripples in regular oscillatory flow. Journal of Geophysical Research 112, F02012, doi:10.1029/2006JF000614.

Van Rijn, L. C., Ribberink, J. S., Van Der Werf, J., Walstra, D. J. R., 2013. Coastal sediment dynamics: recent advances and future research needs. Journal of Hydraulic Research 51, 475-493.

Voulgaris, G., Collins, M. B., 2000. Sediment resuspension on beaches: response to breaking waves. Marine Geology 167, 167-187. 
Walstra, D. J. R., Reniers, A. J. H. M., Ranasinghe, R., Roelvink, J., Ruessink, B. G., 2012. On bar growth and decay during interannual net offshore migration. Coastal Engineering 60, 190-200.

Yoon, H. D., Cox, D. T., 2010. Large-scale laboratory observations of wave breaking turbulence over an evolving beach. Journal of Geophysical Research 115, C10007, doi:10.1029/2009JC005748.

Yoon, H. D., Cox, D. T., 2012. Cross-shore variation of intermittent sediment suspension and turbulence induced by depth-limited wave breaking. Continental Shelf Research 47, 93-106.

Zhang, D., Sunamura, T., 1990. Conditions for the occurrence of vortices induced by breaking waves. Coastal Engineering in Japan 33, 145-155. 
Table 1: Hydrodynamic conditions during the BARDEXII experiment.

\begin{tabular}{lcccc} 
Test & $\boldsymbol{H}_{\boldsymbol{m} \mathbf{0}}(\mathbf{m})$ & $\boldsymbol{T}_{\boldsymbol{p}}(\mathbf{s})$ & $\overline{\boldsymbol{\zeta}}(\mathbf{m})$ & $\boldsymbol{Q}_{\boldsymbol{b}}(\boldsymbol{x}=\mathbf{6 5 m})$ \\
\hline \hline A1 & 0.89 & 8 & 3 & 0.07 \\
A2 & 0.88 & 8 & 3 & 0.09 \\
A3 & 0.88 & 8 & 3 & 0.07 \\
A4 & 0.88 & 8 & 3 & 0.11 \\
A6 & 0.69 & 12 & 3 & 0.01 \\
A7 & 0.77 & 12 & 3 & 0.05 \\
A8 & 0.77 & 12 & 3 & 0.04 \\
\hline B1 & 0.89 & 8 & 3 & $0.03-0.08$ \\
B2 & 0.87 & 8 & 2.5 & $0.17-0.26$ \\
\hline C1 & $0.88,0.55$ & 8 & $2.25-3.65$ & $0.41-0$ \\
C2 & $0.55,0.90$ & 8 & $3.53-2.25$ & $0-0.48$ \\
\hline D1 & 0.74 & 4 & $3.15-4.2$ & 0 \\
D2 & 0.79 & 5 & $3.45-4.05$ & 0 \\
D3 & 0.80 & 6 & $3.45-3.9$ & 0 \\
D4 & 0.83 & 7 & $3.45-3.9$ & 0 \\
D5 & 0.79 & 8 & $3.45-3.75$ & 0 \\
D6 & 0.81 & 9 & $3.30-3.75$ & 0 \\
D7 & 0.81 & 10 & $3.15-3.6$ & 0 \\
\hline E1 & 0.90 & 8 & 3.9 & 0
\end{tabular}




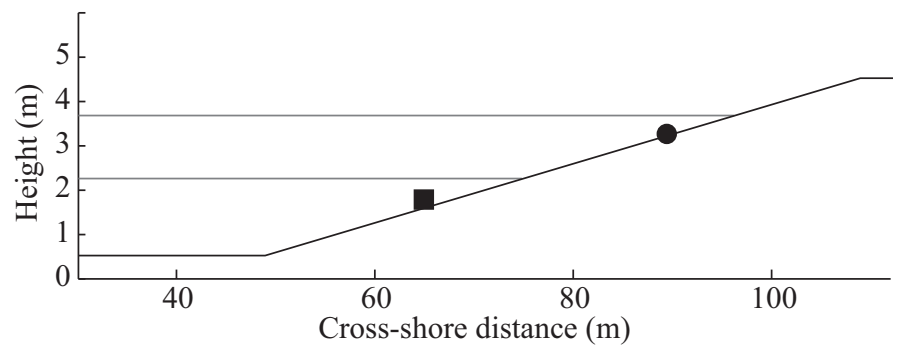

Figure 1: Initial beach profile during the BARDEXII experiment. The cross-shore distance is 0 at the wavemaker. The vertical distance is positive upward from the concrete floor. The square represents the location of the surf rig and the circle the location of the Vectrino profilers in the swash zone. The grey lines represent the lowest and highest still water level during the cases described in this paper, see Table 1.
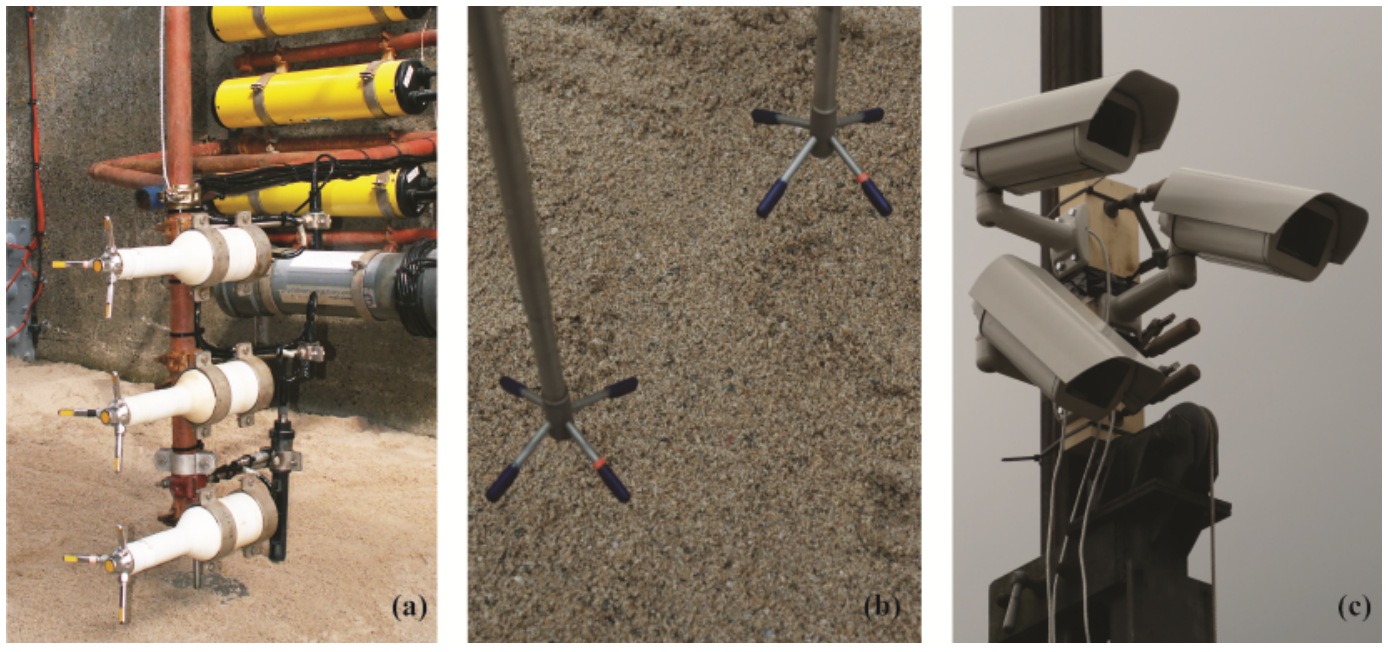

Figure 2: Instruments during the BARDEXII experiment of which the measurements were used in this paper, with (a) the surf rig containing three ADVs and one PT, (b) the Vectrino profilers in the swash zone and (c) three Argus-style cameras. 

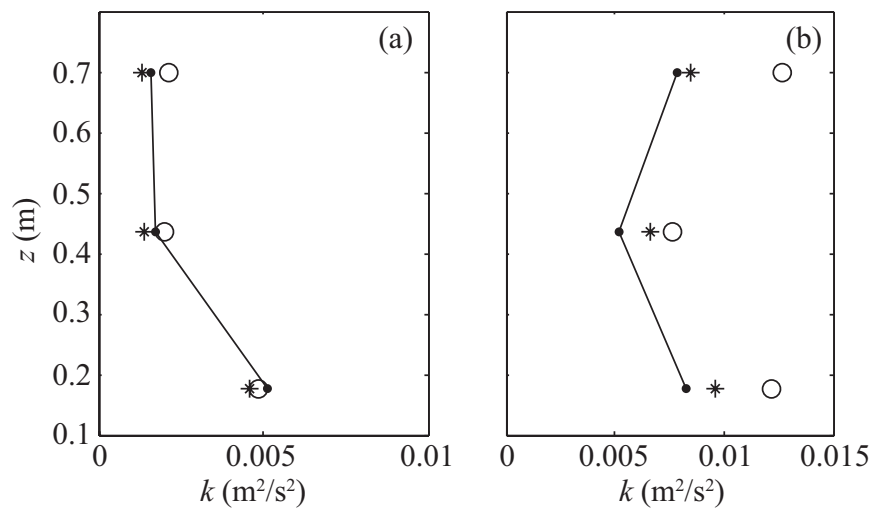

Figure 3: Vertical structure of turbulent kinetic energy $k$ for a (a) monochromatic and (b) bichromatic run. The turbulent kinetic energy is estimated with the (solid line) ensembleaverage and with the two-sensor filtering technique with (circles) large vertical separation between sensors $(1(3)$ and $3(1))$ and $2(1)$ and (asterisks) small vertical separation distance $(1(2)$ and $3(2))$ and $2(3)$.
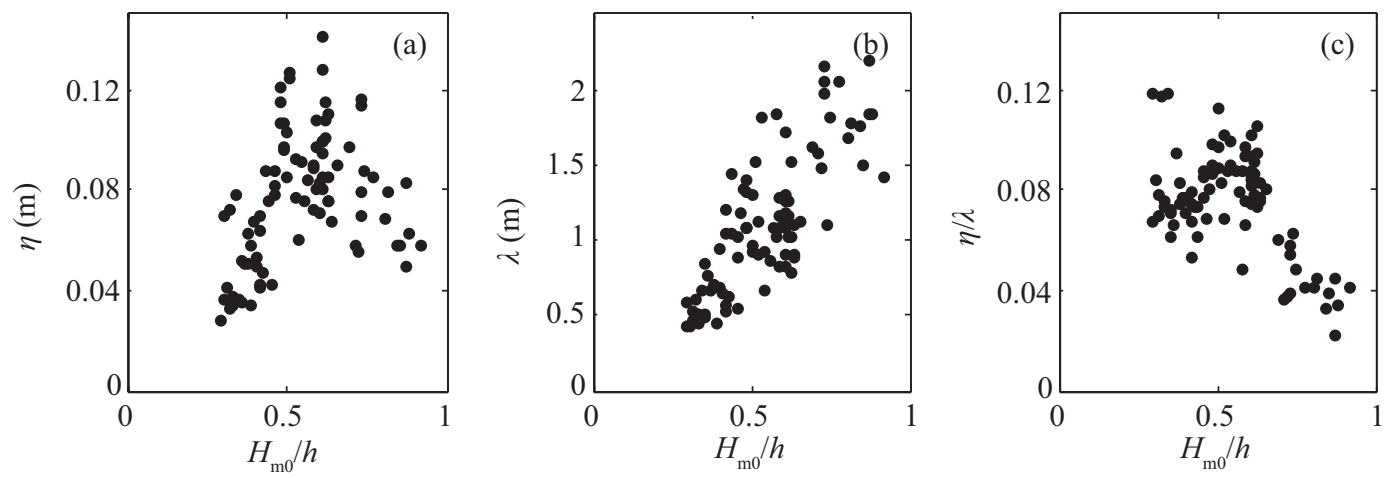

Figure 4: Ripple dimensions at the location of the surf rig $(x=65 \mathrm{~m})$ : (a) ripple height $\eta$, (b) ripple length $\lambda$ and (c) ripple steepness $\eta / \lambda$ versus relative wave height $H_{m 0} / h$. 

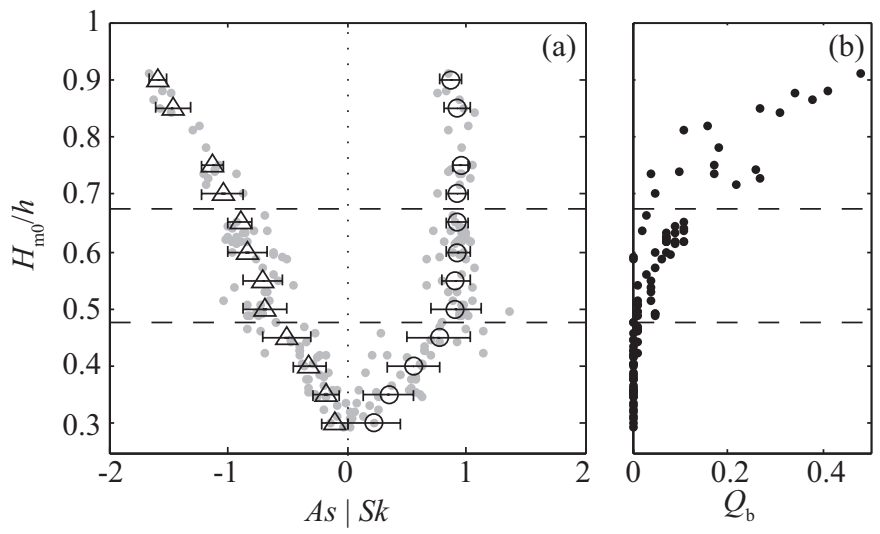

Figure 5: Wave characteristics at the location of the surf rig, with (a) asymmetry As and skewness $S k$ and (b) fraction of broken waves $Q_{b}$ versus relative wave height $H_{m 0} / h$. The grey dots in (a) show observed values for the $S k$ and $A s$, the (triangles) $A s$ and (circles) $S k$ are the $H_{m 0} / h$ bin-averaged values with a bin width of 0.05 . The error bars are \pm the standard deviation within each bin. The dashed horizontal lines represent the chosen values to divide the cases in non-breaking, occasional breaking and breaking (surf zone). 


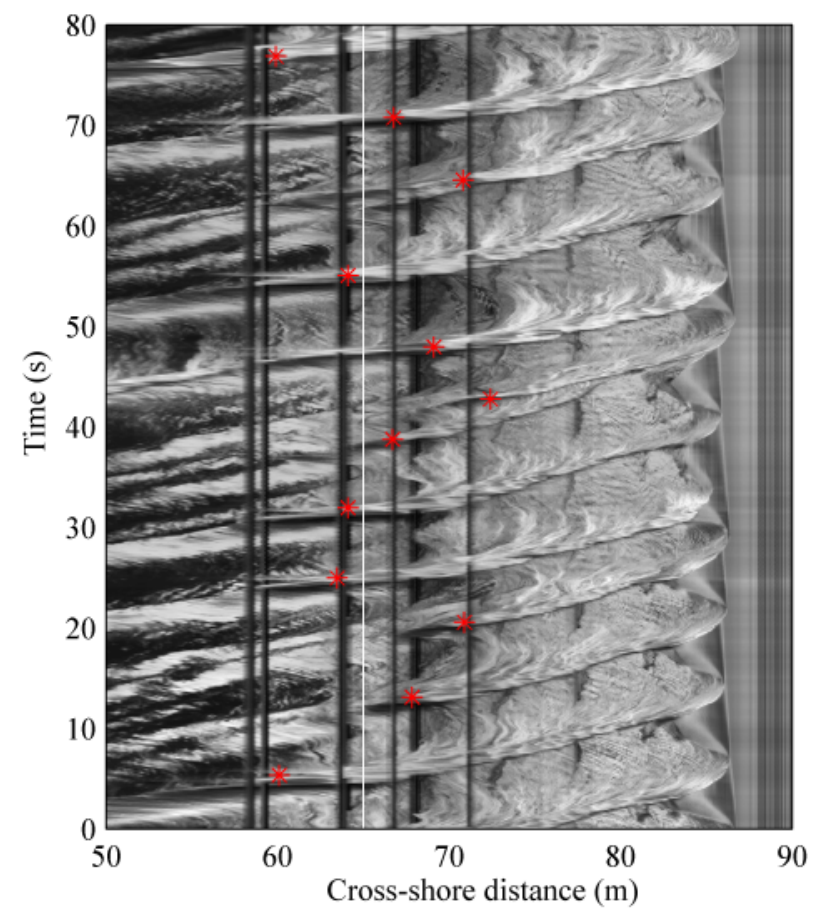

Figure 6: An example of a cross-shore timestack of pixel intensity, collected during run 2 of test series C1. The white vertical line indicates the location of the surf rig and red stars are the manually detected location of wave breaking. 


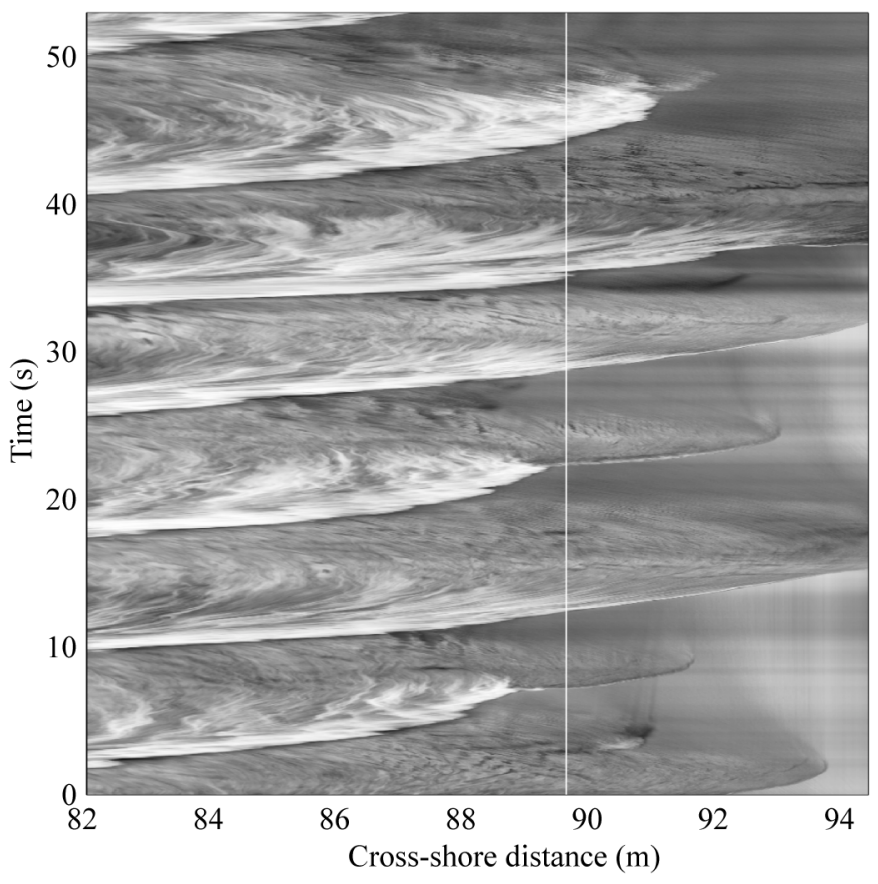

Figure 7: An example of a cross-shore timestack of pixel intensity, collected during run 5 of test series A2. The white vertical line indicates the location of the swash-zone turbulence dissipation measurements. 

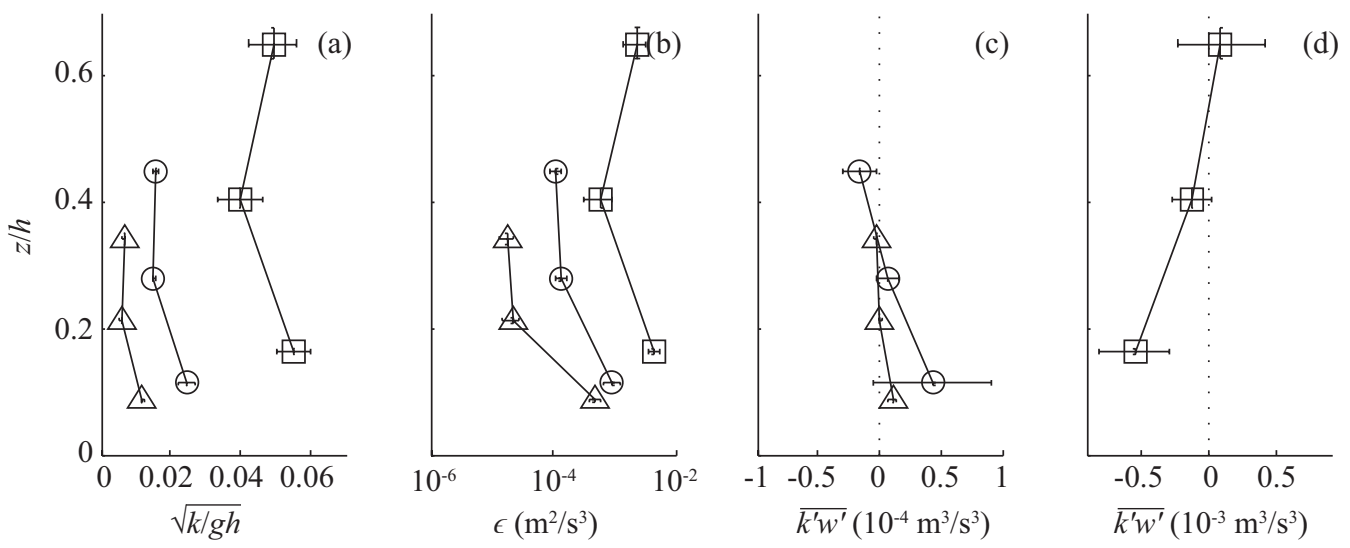

Figure 8: Mean values of (a) Froude-scaled turbulent kinetic energy $\sqrt{k / g h}$, (b) turbulence dissipation $\epsilon$ and (c-d) vertical turbulent flux $\overline{k^{\prime} w^{\prime}}$, versus vertical position relative to water depth $h$. The different symbols represent the classes (triangles) $H_{m 0} / h<0.475$, (circles) $0.475>H_{m 0} / h>0.675$ and (squares) $H_{m 0} / h>0.675$. Vertical and horizontal brackets are \pm the standard error of the mean. Note there is a factor ten difference between the (c) and (d). 

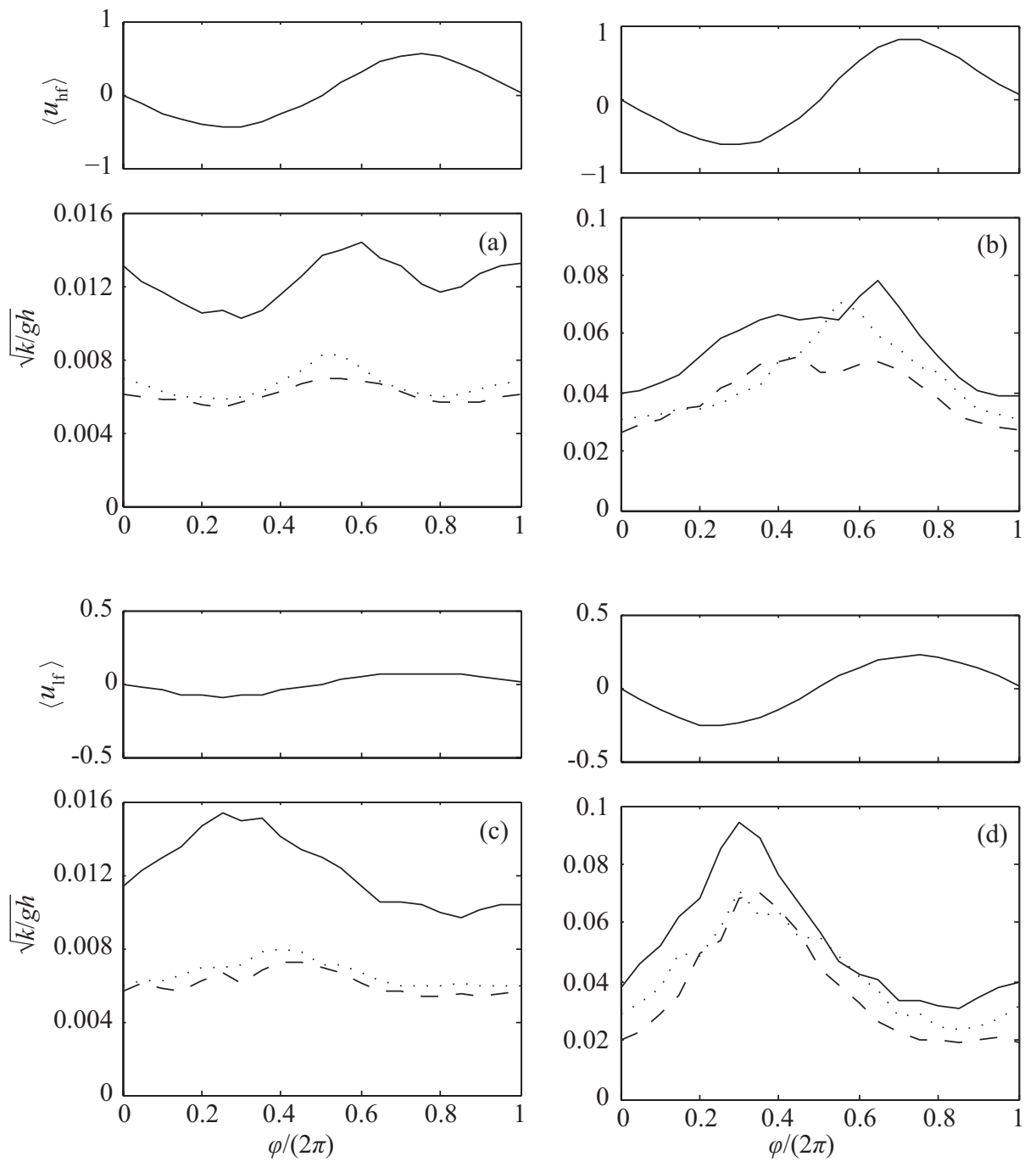

Figure 9: Intra-wave variability of $\sqrt{k /(g h)}$ for (a,c) non-breaking and (b,d) breaking waves within $(a, b)$ short wave orbital motion and $(c, d)$ infragravity motion. The three lines represent the froude-scaled turbulence at (solid line) $0.175 \mathrm{~m}$, (dashed line) 0.435 $\mathrm{m}$ and (dotted line) $0.7 \mathrm{~m}$ above the bed. The plots above each subplot denote phaseaveraged $u_{h f}$ or $u_{l f}$ over all waves used in the analysis. 

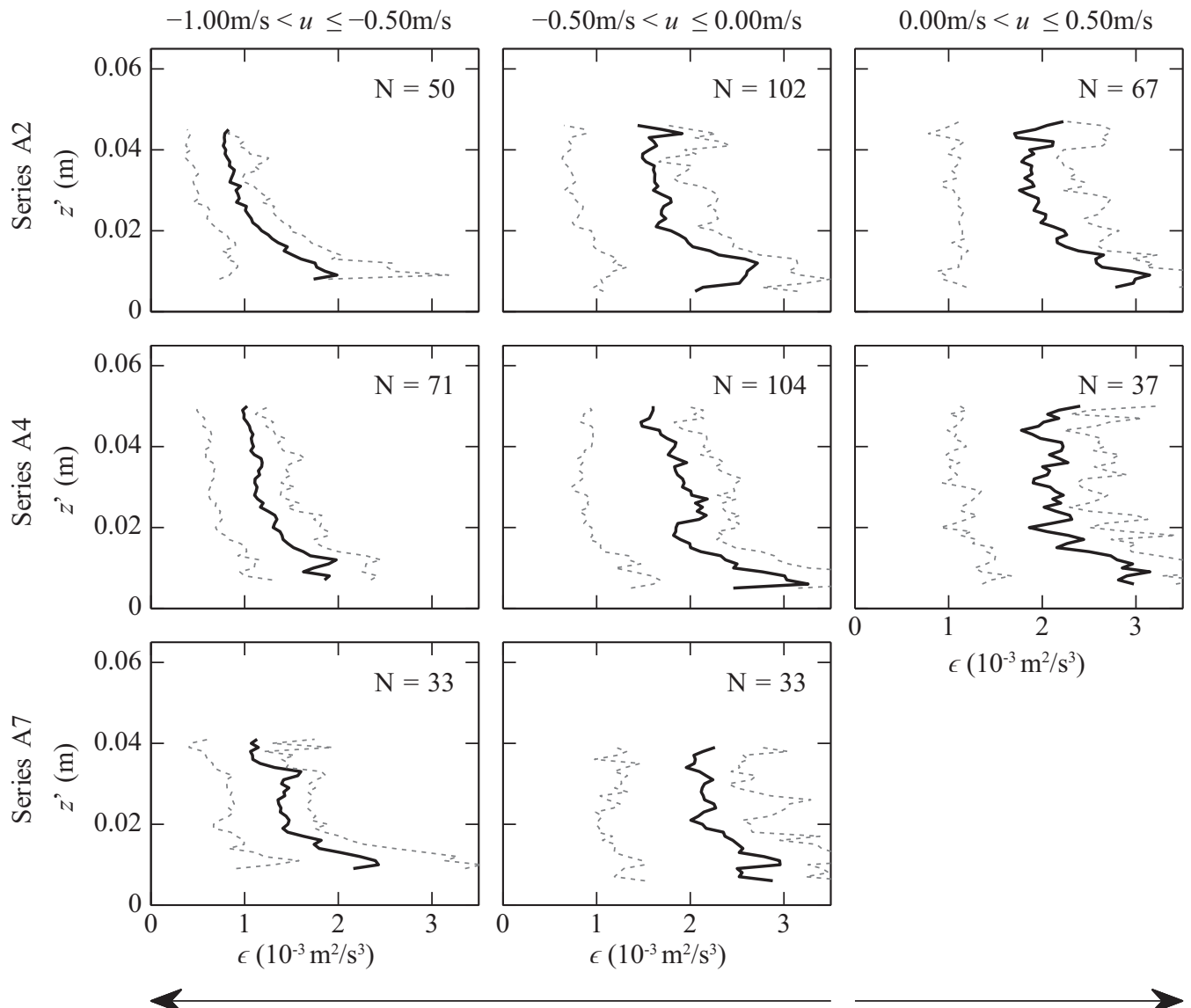

BACKWASH

UPRUSH

Figure 10: Vertical dissipation rate profiles, bin-averaged according to cross-shore velocity. Solid black line indicates bin average, dotted gray lines indicate $25 \%$ and $75 \%$ percentiles. Horizontal and vertical axes are the same for each panel. 

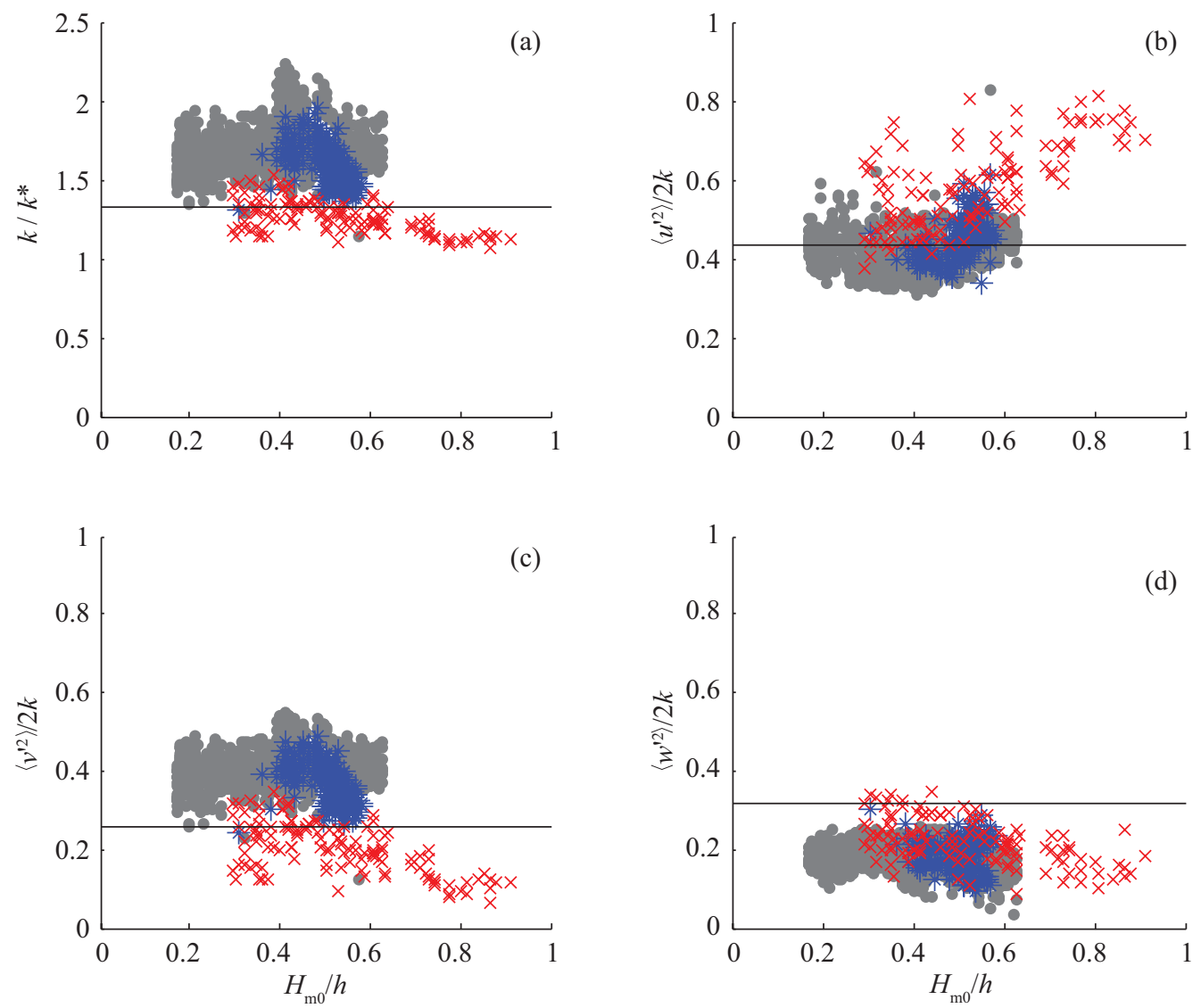

Figure 11: Distribution of (a) $k / k^{*}$, (b) $\left\langle u^{\prime 2}\right\rangle / 2 k$, (c) $\left\langle v^{\prime 2}\right\rangle / 2 k$ and (d) $\left\langle w^{\prime 2}\right\rangle / 2 k$ versus relative wave height $H_{m 0} / h$ from (red crosses) BARDEXII observations, (grey dots) Ameland (Ruessink et al., 2012a) and (blue stars) Truc Vert (Ruessink, 2010). The solid lines show the value for plane wake turbulence (Svendsen, 1987) 